\title{
AREAS BÁSICAS
}

\section{AVALIAÇÃO DA RESPOSTA AO FOTOPERÍODO EM GENÓTIPOS DE ARROZ IRRIGADO $\left({ }^{\mathbf{1}}\right)$}

\author{
NEREU AUGUSTO STRECK $\left({ }^{2 *}\right)$; LEOSANE CRISTINA BOSCO $\left({ }^{3}\right)$; SIMONE MICHELON $\left({ }^{4}\right)$; \\ HAMILTON TELLES ROSA $\left({ }^{5}\right)$; LIDIANE CRISTINE WALTER $\left({ }^{6}\right)$; GIZELLI MOIANO DE PAULA $\left({ }^{5}\right)$; \\ CÁTIA CAMERA $\left({ }^{5}\right)$; ISABEL LAGO $\left({ }^{7}\right)$; ELIO MARCOLIN $\left({ }^{8}\right)$
}

\begin{abstract}
RESUMO
A temperatura e o fotoperíodo são os fatores ambientais principais que influenciam a duração do ciclo de desenvolvimento das plantas de arroz (Oryza sativa L.). A resposta fotoperiódica da maioria dos genótipos modernos de arroz usados no sul do Brasil ainda não foi quantificada. O objetivo do trabalho foi identificar a resposta ao fotoperíodo de algumas cultivares de arroz irrigado cultivadas nessa região. Um experimento de campo foi instalado em Santa Maria (RS), durante os anos agrícolas de 2003/2004 e 2004/2005 com cinco épocas de semeadura por ano. Em 2003/2004, as épocas de semeadura foram $1 .^{\circ} / 9 /$ $2003,20 / 10 / 2003,21 / 11 / 2003,5 / 1 / 2004$ e 29/1/2004 e em 2004/2005, as épocas de semeadura foram 2 / $9 / 2004,7 / 10 / 2004,4 / 11 / 2004,3 / 12 / 2004$ e 2/3/2005. As cultivares utilizadas foram IRGA 421, IRGA 416, IRGA 417, IRGA 420, BR-IRGA 409, BRS 7 "Taim" e EPAGRI 109, todas do tipo moderno, com diferentes ciclos de desenvolvimento, de muito precoce (IRGA 421) a tardio (EPAGRI 109). O delineamento experimental foi um trifatorial (cultivar, data de semeadura e ano agrícola) inteiramente casualizado com quatro repetições. Cada repetição consistiu de um balde de 12 litros de capacidade com 10 plantas, cinco das quais foram marcadas com arames coloridos e avaliadas quanto ao número final de folhas no colmo principal (NFF). Calculou-se o fotoperíodo acumulado na fase em que o arroz é sensível ao fotoperíodo. Foi verificado um aumento linear do NFF com o fotoperíodo acumulado em todas as cultivares, o que indica uma resposta fotoperiódica típica de planta de dia curto nos genótipos de arroz. Houve diferença de sensibilidade ao fotoperíodo entre as cultivares.
\end{abstract}

Palavras-chave: número de folhas, fase juvenil, fase indutiva, época de semeadura.

( $\left.{ }^{1}\right)$ Recebido para publicação em 24 de janeiro de 2006 e aceito em 11 de julho de 2006.

(2) Departamento de Fitotecnia, Centro de Ciências Rurais (CCR), Universidade Federal de Santa Maria (UFSM), 97105-900 Santa Maria (RS), Brasil E-mail: nstreck1@smail.ufsm.br. *Autor para correspondência.

$\left({ }^{3}\right)$ Estudante do curso de graduação em Agronomia, CCR, UFSM. Bolsista do PIBIC/CNPq/UFSM.

$\left({ }^{4}\right)$ Estudante do Programa de Pós-Graduação em Agronomia, UFSM, Santa Maria (RS), Brasil. Bolsista CAPES.

$\left({ }^{5}\right)$ Estudante do curso de graduação em Agronomia, CCR, UFSM.

$\left({ }^{6}\right)$ Estudante do curso de graduação em Agronomia, CCR, UFSM. Bolsista da FIPE.

${ }^{7}$ ) Estudante do curso de graduação em Agronomia, CCR, UFSM. Bolsista da FAPERGS.

$\left({ }^{8}\right)$ Estação Experimental do Arroz - Instituto Rio Grandense do Arroz (IRGA), Rua Bonifácio Carvalho Bernardes, 1494, Caixa Postal 29, 94930-030 Cachoeirinha (RS), Brasil. 


\title{
ABSTRACT \\ EVALUATION OF THE PHOTOPERIODIC RESPONSE IN PAD RICE GENOTYPES
}

\begin{abstract}
Temperature and photoperiod are major environmental factors that affect the development of rice (Oryza sativa L.). The photoperiodic response of the majority of modern rice genotypes grown in Southern Brazil has not been quantified yet. The objective of this study was to investigate the photoperiodic response in some rice cultivars grown in Southern Brazil. A two-year field experiment during the 2003/2004 and $2004 / 2005$ growing seasons was carried out with five sowing dates each year. The 2003/2004 sowing dates were (day/month/year) $9 / 1 / 2003,10 / 20 / 2003,11 / 21 / 2003,1 / 5 / 2004$, and $1 / 29 / 2004$ and in 2004/ 2005 the sowing dates were $9 / 2 / 2004,10 / 7 / 2004,4 / 11 / 2004,12 / 3 / 2004$, and 3/2/2005. The cultivars studied were: IRGA 421, IRGA 416, IRGA 417, IRGA 420, BR-IRGA 409, BRS 7 “Taim” and EPAGRI 109, all modern type rice genotypes with different developmental cycle, varying from very early (IRGA 421) to late (EPAGRI 109). The experiment was a three-factorial (cultivar, sowing date, and growing season) in a completely randomized design with four replicates. Each replicate consisted of a 12L pot with 10 plants, five of them tagged with colored wires. The main stem final leaf number (FLN) was measured on the tagged plants. Daily photoperiod was calculated and accumulated during the inductive phase. A linear increase of FLN with accumulated photoperiod was observed in all cultivars, indicating a typical shortday response in the rice genotypes tested. Differences in the sensitivity to photoperiod among cultivars were observed.
\end{abstract}

Key words: leaf number, juvenil phase, inductive phase, sowing time.

\section{INTRODUÇÃO}

O arroz (Oryza sativa L.) é uma das culturas de maior importância social e econômica do mundo. No mundo todo, a área cultivada com arroz anualmente é de cerca de 150 milhões de hectares (UsDA, 2005) e esse cereal constitui a dieta básica de dois terços da população do planeta (LuZZARDI, et al., 2005; FERREIRA et al., 2005). O arroz é um dos principais produtos que compõem a cesta básica e a principal fonte calórica entre os grãos, fornecendo $21 \%$ das calorias e $14 \%$ das proteínas necessárias ao ser humano (FAPEMIG, 2005; FERREIRA et al., 2005). O Brasil é o maior produtor de arroz da América Latina sendo cultivados, anualmente, cerca de quatro milhões de hectares com arroz (FERREIRA et al., 2005). Cerca de $25 \%$ das lavouras brasileiras de arroz, ou seja, em torno de um milhão de hectares, estão situadas nas várzeas do Estado do Rio Grande do Sul, com produtividade média, na safra 2004/2005, de 6,11 tha ${ }^{-1}$ (IRGA, 2005). Portanto, a pesquisa e sua aplicação na cadeia produtiva do arroz têm o potencial de afetar o bem-estar e a economia de um considerável número de pessoas.

O ciclo de desenvolvimento, ou a fenologia, desempenha um papel importante na determinação do rendimento da cultura do arroz (HORIE, 1994; FUKAI, 1999). Para a obtenção de altos rendimentos, as fases de desenvolvimento devem ocorrer quando as condições ambientais são as mais favoráveis possíveis para que a planta possa maximizar a utilização dos recursos do meio. A duração, em dias, do ciclo de desenvolvimento de qualquer vegetal, incluindo o arroz, depende fundamentalmente de dois fatores: o genótipo e o ambiente. Como exemplo do primeiro fator há genótipos de arroz de ciclo muito precoce a tardio (SOSBAI, 2005) enquanto o alongamento do ciclo de desenvolvimento de um mesmo genótipo de arroz em semeaduras precoces em relação a semeaduras tardias (Michelon, 2006; STRECK et al., 2006) é um exemplo do segundo fator.

A temperatura é o principal fator ambiental que afeta a duração do ciclo de desenvolvimento da planta de arroz (HodGes, 1991; GAO et al., 1992; Sié et al., 1998). Além da temperatura, o fotoperíodo também afeta o ciclo de desenvolvimento de espécies selvagens de Oryza e de muitas variedades de arroz cultivadas comercialmente (VERGARA et al., 1969; BAKER et al., 1990; Horie, 1994; FuKaI, 1999). Em alguns sistemas e locais de cultivo de arroz, a resposta genotípica ao fotoperíodo é mais importante do que a resposta à temperatura para alcançar altos rendimentos, como por exemplo, em terras baixas e sem irrigação em regiões tropicais, onde a fonte de água para a cultura provém das chuvas freqüentes durante o período das monções (FUKAI, 1999). Nesses locais, a temperatura do ar é próxima da ótima para arroz e varia pouco ao longo do ano e a época de floração deve ocorrer antes do fim do período de chuvas das monções para que não haja deficiência hídrica no solo durante a fase de enchimento de grãos. Geralmente, nesses locais, consegue-se mais sucesso com o uso de genótipos sensíveis ao fotoperíodo do que com genótipos insensíveis ao fotoperíodo (COOPER et al., 1999; FUKAI, 1999; WADE et al., 1999).

A resposta da maioria das cultivares de arroz ao fotoperíodo caracteriza-se pelo aumento do número final de folhas (NFF) no colmo principal e pelo atraso 
do florescimento à medida que o fotoperíodo aumenta, sendo o arroz classificado como planta de dia curto (VERgARA et al., 1969; BAKER et al., 1990, KAWAKAIA e YAJIMA, 1995). A sensibilidade ao fotoperíodo em genótipos de arroz não ocorre durante todo o ciclo de desenvolvimento da planta. Plantas de arroz não respondem ao fotoperíodo logo após a emergência durante o período chamado de fase juvenil, por alguns autores (HoriE e NAKAGAWA, 1990; HorIE, 1994), ou fase vegetativa básica, por outros (VERGARA et al., 1969; Y IN et al., 1997a). A duração dessa fase, em dias, varia em vista da temperatura e do genótipo (YIN et al., 1997a; FUKAI, 1999) e termina quando a planta tem aproximadamente seis folhas na haste principal (YIN et al., 1997a; LEE et al, 2001). A fase em que a planta responde ao fotoperíodo tem início no fim da fase juvenil e se estende até dois ou três dias após a diferenciação da panícula (ponto de algodão, estágio R1 da escala de COUNCE et al., 2000) quando faltam ainda aproximadamente três folhas para aparecer a folha bandeira (YIN e KROPFF, 1998; LEE et al, 2001), e é chamada de fase indutiva (YIN et al., 1997a; FUKAI, 1999). Após a fase indutiva, a planta de arroz novamente não responde mais ao fotoperíodo até a maturação fisiológica dos grãos, sendo denominada fase pósindutiva (YIN et al., 1997a; FUKAI, 1999; LEE et al, 2001).

O conhecimento da resposta fotoperiódica das cultivares de arroz é importante para identificar sua adaptação para cultivo em diferentes locais e assim auxiliar na determinação da época de semeadura recomendada para cada região. Quantificar a resposta fotoperiódica dos genótipos também é importante em modelos de simulação do desenvolvimento dessa espécie, os quais devem levar em conta os principais fatores ambientais que afetam o desenvolvimento do arroz (HodGES, 1991; GAO et al., 1992; SUMMERFIELD et al., 1992; Horie, 1994; Yin et al., 1997b).

Uma das maneiras de identificar o efeito do fotoperíodo sobre o desenvolvimento do arroz é por meio de experimentos de campo com várias semeaduras ao longo do ano contando-se o NFF do colmo principal (KaWAKATA e YAJIMA, 1995; Y IN e KROPFF, 1996). Havendo diferença no NFF entre as épocas, o fotoperíodo é um fator ecológico que afeta o ciclo de um mesmo genótipo entre épocas, já que estando a planta exposta ao fotoperíodo indutivo, menor número de primórdios se diferenciam em folhas no ápice meristemático (HorIE, 1994).

No sul do Brasil, predominam os genótipos de arroz da subespécie indica, os quais têm sido relatados como de maior resposta fotoperiódica do que os genótipos da subespécie japonica (FUKAI, 1999). Um levantamento da literatura revelou que se desconhece a resposta do número final de folhas da maioria dos genótipos modernos de arroz usados no sul do Brasil em diferentes épocas de semeadura e sua relação com o fotoperíodo, o que constitui o incentivo para este esforço científico. O objetivo do trabalho foi identificar a resposta ao fotoperíodo de algumas cultivares de arroz irrigado cultivadas no sul do Brasil. A hipótese deste trabalho foi de que existe resposta fotoperiódica desses genótipos de arroz.

\section{MATERIAL E MÉTODOS}

Um experimento de campo foi desenvolvido na área experimental do Departamento de Fitotecnia da Universidade Federal de Santa Maria, Santa Maria, RS (latitude: $29^{\circ} 43^{\prime} \mathrm{S}$, longitude: $53^{\circ} 43^{\prime} \mathrm{W}$ e altitude: $95 \mathrm{~m}$ ) em dois anos agrícolas (2003/2004 e 2004/2005). O clima da região, segundo a classificação de Köppen, é Cfa, ou seja, Subtropical úmido sem estação seca definida com verões quentes (MORENO, 1961). O solo do local é uma transição entre a Unidade de Mapeamento São Pedro (Argissolo Vermelho distrófico arênico) e a Unidade de Mapeamento Santa Maria (Alissolo Hipocrômico argilúvico típico) (EMBrAPA, 1999). A variação do fotoperíodo ao longo do ano em Santa Maria é de cerca de 11 a 15 horas (KiesLing, 1982).

Foram utilizados sete genótipos de arroz, pertencentes ao tipo moderno (porte baixo, folhas eretas) e subespécie indica: EPAGRI 109, BR-IRGA 409, IRGA 416, IRGA 417, BRS 7 "Taim", IRGA 420 e IRGA 421. Esses genótipos são recomendados para o Rio Grande do Sul (SoSBAI, 2005) e representam grupos de genótipos de ciclo distinto, variando de muito precoce (IRGA 421) a tardio (EPAGRI 109). Foram selecionadas cinco épocas de semeadura por ano agrícola: 1. \% /9/ 2003, 20/10/2003, 21/11/2003, 5/1/2004 e 29/1/2004 no ano agrícola 2003/2004, e 2/9/2004, 7/10/2004, $4 / 11 / 2004,3 / 12 / 2004$ e 2/03/2005 no ano agrícola $2004 / 2005$. Essas épocas de semeadura foram escolhidas a fim de e ter plantas de arroz crescendo e desenvolvendo antes, durante e após a época recomendada à cultura do arroz irrigado na região central do Rio Grande do Sul, que é de 15/11 a 10/12 (SosBAI, 2005). Desse modo, as plantas estavam expostas a diferentes condições de fotoperíodo e temperatura do ar ao longo do seu crescimento e desenvolvimento.

A semeadura e o cultivo das plantas ocorreu a campo em baldes plásticos pretos de $30 \mathrm{~cm}$ de diâmetro e $26 \mathrm{~cm}$ de altura, com capacidade de 12 litros, preenchidos com solo do local e enterrados, deixando-se uma borda de $5 \mathrm{~cm}$ acima do nível do solo. O espaçamento entre os baldes (centro a centro) foi de 1,5 x 0,8 m. Foram semeadas 30 sementes por balde. Na primeira época de semeadura do ano agrícola 2004/2005 fez-se a pré-germinação das sementes em laboratório a $25{ }^{\circ} \mathrm{C}$ por cinco dias para acelerar a emergência das plântulas nesta época que tinha sido muito lenta no ano anterior. 
O experimento foi um trifatorial (cultivar, data de semeadura e ano agrícola) no delineamento inteiramente casualizado com quatro repetições (baldes). O dia da emergência foi considerado quando $50 \%$ das plântulas de cada balde estavam com o prófilo visível acima do nível do solo. No estágio V3 da escala de COUNCE et al. (2000) foi feito o raleio, deixando-se dez plântulas por balde, cinco das quais foram marcadas, aleatoriamente, com arames coloridos. Neste estágio de desenvolvimento foi iniciada a irrigação de modo a manter uma lâmina constante de água de, aproximadamente, $5 \mathrm{~cm}$ até o final do ciclo de desenvolvimento do arroz. A irrigação foi realizada com água de torneira com uso de mangueiras. A irrigação foi feita diariamente e durante os meses de verão (dezembro, janeiro e fevereiro) sendo necessárias duas a três irrigações por dia. A adubação das plantas seguiu as recomendações da cultura do arroz irrigado (SOSBAI, 2005), com base na análise química do solo realizada antes da semeadura da primeira época. Usou-se $20 \mathrm{~g} /$ balde de adubo 7-11-9 por ocasião da semeadura, e a adubação de cobertura de nitrogênio foi feita em duas vezes, a primeira no início do perfilhamento e a segunda na diferenciação da panícula ou ponto de algodão, usando-se $8,5 \mathrm{~g} /$ balde de uréia.

O número de folhas no colmo principal das cinco plantas marcadas por balde foi contado semanalmente até que a planta emitisse a folha bandeira, ou seja, a última folha, quando foi obtido o NFF por planta. A média do NFF por repetição foi obtida pela média das cinco plantas marcadas em cada balde. Nas plantas marcadas foi também registrada a data da maturação fisiológica, considerada quando as plantas estavam no estágio R9 da escala de COUNCE et al. (2000).

O fotoperíodo diário (considerando-se a duração do crepúsculo civil de $6^{\circ}$ abaixo do plano do horizonte) foi calculado com o algoritmo de KIESLING (1982) durante a fase em que o arroz é sensível ao fotoperíodo. Foi considerado como fase indutiva o período entre o aparecimento da sexta folha e o da folha NFF-3 no cartucho do colmo principal. Os dados diários de fotoperíodo foram acumulados durante a fase indutiva. Optou-se pelo fotoperíodo acumulado (FA) durante a fase indutiva por entender-se que, quando as plantas de arroz são cultivadas no campo, o FA é mais realístico do que o fotoperíodo médio durante a fase indutiva, pois nessa condição o fotoperíodo é diferente a cada dia e a planta responde a um efeito acumulado do fotoperíodo (HorIE, 1994).

Os dados meteorológicos (temperatura mínima e máxima do ar e precipitação pluvial) diários foram medidos na Estação Climatológica Principal do $8^{\circ}$
Distrito de Meteorologia - Instituto Nacional de Meteorologia, localizada a aproximadamente $250 \mathrm{~m}$ da área experimental. A soma térmica $\left({ }^{\circ} \mathrm{C}\right.$ dia $)$ da fase EM-R9 foi calculada pelo somatório da diferença entre a temperatura média diária (média aritmética entre a temperatura mínima e máxima diária do ar) e a temperatura base de $11^{\circ} \mathrm{C}$ (Michelon et al., 2006; STRECK et al., 2006).

Foi realizada a análise de variância da variável número final de folhas para avaliar o efeito das fontes de variação (época de semeadura, ano agrícola e cultivar) e calculada a diferença mínima significativa (DMS) a $5 \%$ de probabilidade de erro. A relação NFF x FA foi testada através de regressão linear simples. Uma relação linear positiva entre as duas variáveis NFF e FA significa uma resposta fotoperiódica típica de planta de dia curto (KAWAKATA e YAJIMA, 1995; Yin e KROPFF, 1996).

\section{RESULTADOS E DISCUSSÃO}

Plantas da cultivar EPAGRI 109, semeadas na época mais tardia nos dois anos agrícolas, não entraram na fase reprodutiva em razão das baixas temperaturas, que foram inferiores a $15{ }^{\circ} \mathrm{C}$ a partir de maio nos dois anos agrícolas (Figura 1), e morreram antes de emitir a folha bandeira; por esse motivo, o NFF dessa cultivar é disponível apenas para quatro épocas na análise dos dados. Plantas de outras cultivares emitiram a folha bandeira em todas as épocas, mas muitas delas não atingiram o estágio R9 na última época de semeadura nos dois anos agrícolas.

O ciclo de desenvolvimento, em dias, da emergência (EM) até a maturação fisiológica (R9) variou com a cultivar e, para uma mesma cultivar, variou com a época de semeadura (Figura 2). A variação de ciclo de desenvolvimento entre cultivares reflete as diferenças genéticas das cultivares, de ciclo muito precoce (IRGA 421), com duração de aproximadamente 100 dias, a ciclo tardio (EPAGRI 109), com duração de aproximadamente 170 dias. Já a duração do ciclo de desenvolvimento de um mesmo genótipo, geralmente, diminuiu à medida que a semeadura foi mais tardia, especialmente no ano agrícola 2004/2005 (Figura 2). Quando a duração do ciclo de desenvolvimento EM-R9 foi representada em soma térmica, com unidade de tempo em ${ }^{\circ} \mathrm{C}$ dia, a tendência de diminuição do ciclo com o atraso da data de semeadura também foi evidente, especialmente na última época de semeadura (Figura 3). O encurtamento do ciclo de desenvolvimento das cultivares de arroz 
com o atraso da data de semeadura (Figuras 2 e 3) é similar aos resultados relatados por FUKAI (1999) e, portanto, sugerem resposta fotoperiódica desses genótipos. Como no campo a temperatura varia dia após dia e durante o dia, o NFF é mais apropriado como indicador da resposta fotoperiódica, pois independe da temperatura e tem uma relação direta com a duração do ciclo de desenvolvimento EM-R9 (Streck et al., 2006). Além disso, a quantidade de dados de NFF é maior do que a duração do ciclo total neste estudo, pois a maioria das cultivares não atingiram $\mathrm{R} 9$ em várias épocas de semeadura tardias (Figuras 2 e 3), enquanto o NFF apenas não foi possível ser medido na cultivar EPAGRI 109 semeada na última data de semeadura.
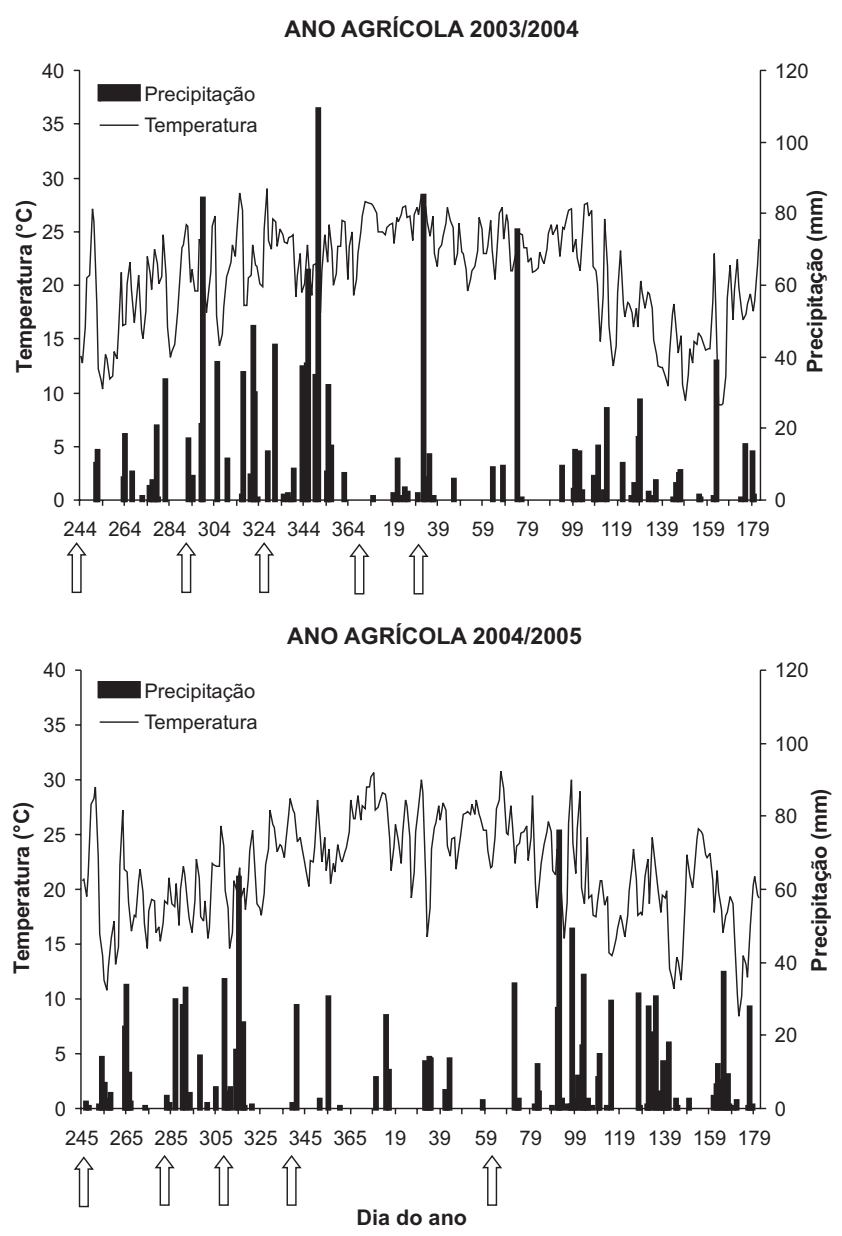

Figura 1. Temperatura média diária do ar e precipitação pluvial diária durante o período experimental nos dois anos agrícolas. Santa Maria, RS. 2003/2005. As setas indicam o dia da semeadura das cinco épocas em cada ano agrícola.
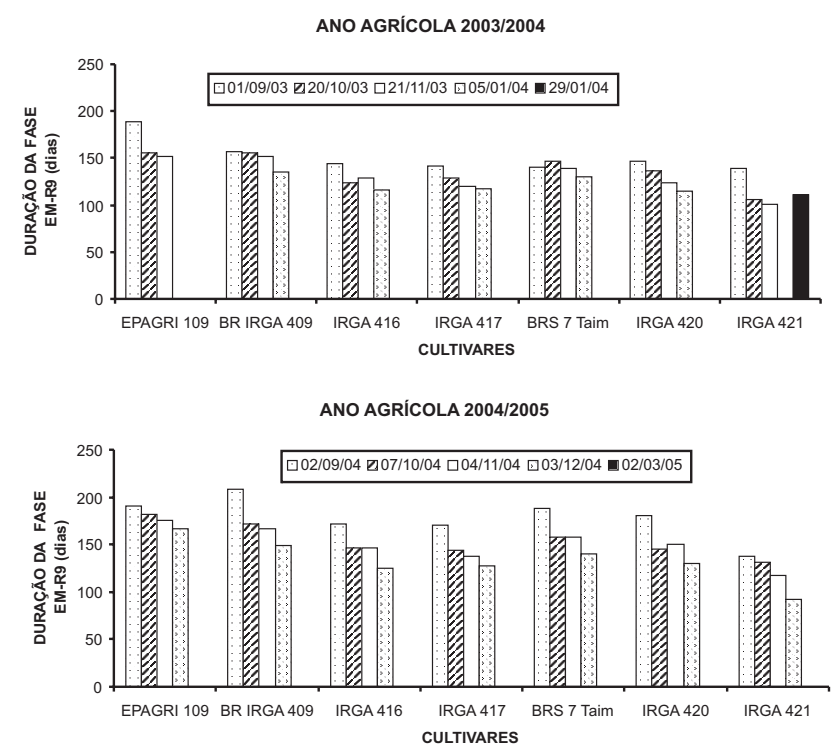

Figura 2. Duração, em dias, do ciclo de desenvolvimento de sete cultivares de arroz irrigado em cinco épocas de semeadura e dois anos agrícolas. Santa Maria, RS. $2003 / 2005$. As datas correspondem às épocas de semeadura (dia/mês/ano). EM = emergência, R9 = maturação fisiológica.
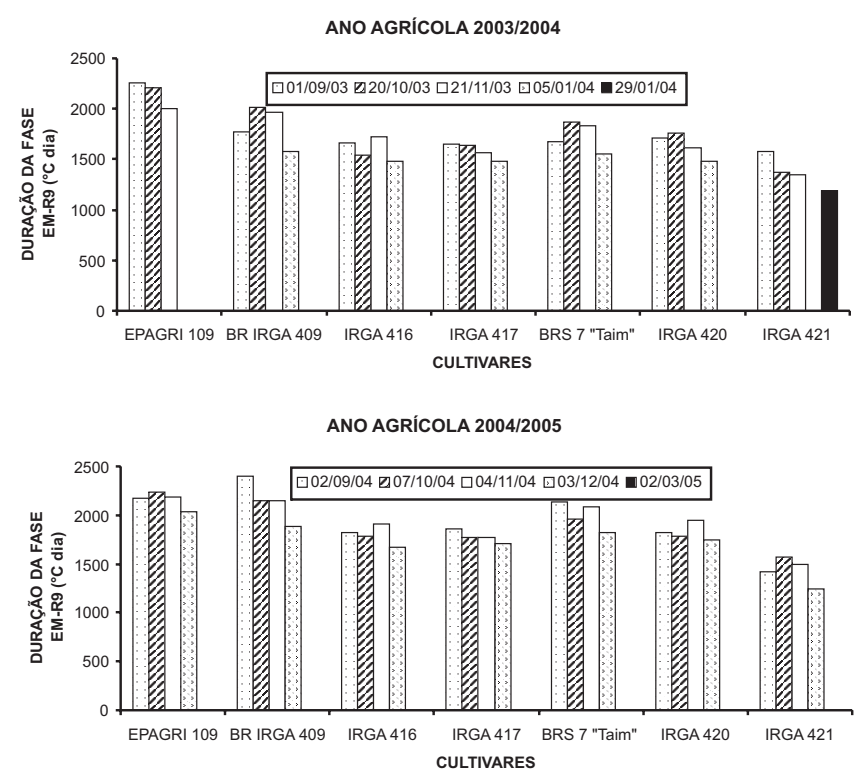

Figura 3. Duração, em ${ }^{\circ} \mathrm{C}$ dia, do ciclo de desenvolvimento de sete cultivares de arroz irrigado em cinco épocas de semeadura e dois anos agrícolas. Santa Maria, RS. $2003 / 2005$. As datas correspondem às épocas de semeadura (dia/mês/ano). EM = emergência, $\mathrm{R} 9=$ maturação fisiológica. 
Tabela 1. Graus de liberdade (GL) e quadrado médio (QM) do quadro da análise de variância para a variável número final de folhas no colmo principal (NFF) em sete cultivares de arroz irrigado cultivadas em cinco épocas de semeadura em dois anos agrícolas. Santa Maria, RS, 2003/2004 e 2004/2005

\begin{tabular}{lcc}
\hline Causa da variação & GL & QM \\
\hline Cultivar & 6 & $103,24^{* *}$ \\
Época de semeadura & 4 & $56,57^{* *}$ \\
Ano agrícola & 1 & $26,50^{* *}$ \\
Ano agrícola *época de semeadura & 4 & $29,55^{* *}$ \\
Ano agrícola *cultivar & 6 & $3,82^{* *}$ \\
Cultivar* época de semeadura & 24 & $2,33^{* *}$ \\
Ano agrícola *cultivar*época de semeadura & 23 & $1,66^{* *}$ \\
\hline
\end{tabular}

** Probabilidade $<0,0001$

A análise de variância para a variável NFF no colmo principal revelou efeito significativo dos fatores cultivar, época de semeadura e ano agrícola e das interações entre os três fatores (Tabela 1). Considerando as causas de variação individuais do NFF, o quadrado médio foi maior para o fator cultivar do que para época de semeadura e ano agrícola (Tabela 1), indicando ter a constituição genética da cultivar maior efeito no NFF do que o ambiente nesses experimentos. O segundo maior quadrado médio foi para o fator época de semeadura, indicando ser o NFF grandemente afetado pela época de semeadura e, portanto, um indicativo da resposta fotoperiódica, já que diferentes épocas resultam em exposição das plantas a diferentes fotoperíodos. Dos três fatores ou causas da variação individuais, o ano agrícola foi o que menos afetou o NFF, mas com efeito significativo, que pode ser atribuído às condições meteorológicas (temperatura do ar e precipitação pluvial, Figura 1) distintas nos dois anos, em grande parte devido às datas de semeadura não terem sido as mesmas nos dois anos.

Como a interação tripla dos fatores sobre o NFF foi significativa (Tabela 1), a análise estatística foi realizada dentro de cada um dos três fatores e os resultados dessa análise estão na figura 4 . Similarmente ao que foi verificado com a duração do ciclo de desenvolvimento (Figuras 2 e 3), o NFF variou com a cultivar e com a época de semeadura (Figura 4), significando que quanto mais longo o ciclo (cultivares tardias ou semeaduras mais cedo), maior o NFF. A cultivar EPAGRI 109 (ciclo tardio ou longo) teve o NFF de 20,3 e 21,6 folhas na primeira época de semeadura dos anos agrícolas de 2003/2004 e 2004 / 2005, respectivamente, e a cultivar IRGA 421 (ciclo muito precoce) na quinta época de semeadura teve um NFF de 12,6 e 10,8 folhas em 2003/2004 e 2004/2005 respectivamente.

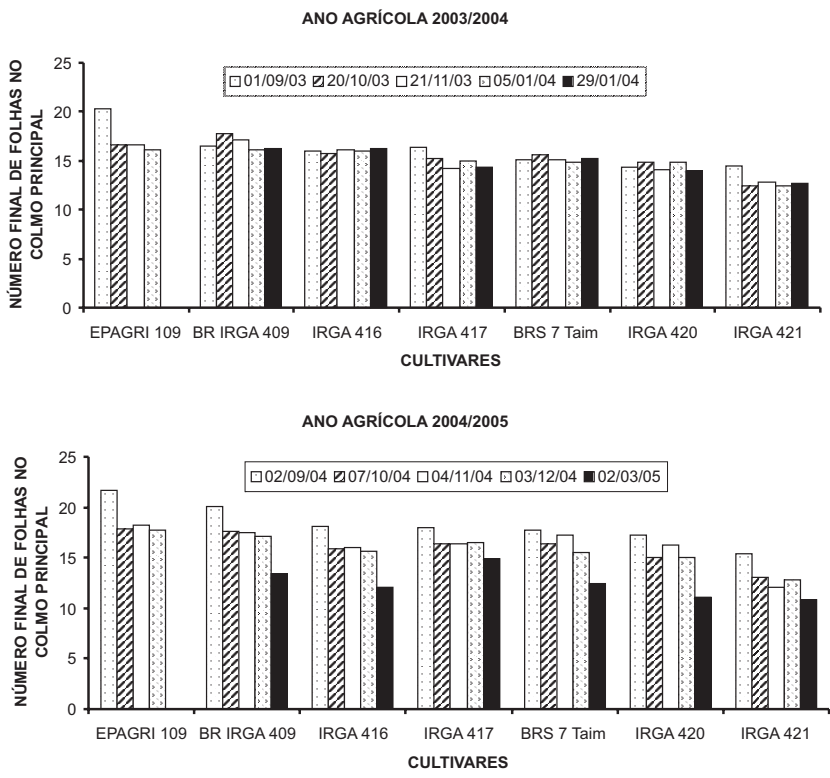

Figura 4. Número final de folhas no colmo principal de sete cultivares de arroz em cinco épocas de semeadura e dois anos agrícolas. A diferença mínima significativa (DMS) à probabilidade $<0,05$ é 1,62 folhas. Santa Maria, RS, 2003/2005. As datas correspondem às épocas de semeadura (dia/mês/ano).

Houve maior diferença de NFF entre a primeira e a última época de semeadura em todas as cultivares de 2004/2005 comparando com 2003/2004 (Figura 4). Esse fato ocorreu devido à emergência das plantas em setembro de 2004 ter ocorrido mais cedo do que em setembro de 2003 e também porque a última época de semeadura foi bem mais tarde em 2005 (2 de março) do que em 2004 (29 de janeiro). Essas diferenças entre os dois anos agrícolas proporcionaram plantas de arroz submetidas à maior variação de fotoperíodo no ano agrícola de 2004/2005 do que em 2003/2004, o que foi importante no estudo, já que aumentou a diferença de NFF entre a primeira e a quinta época de semeadura.

As diferenças de NFF de uma mesma cultivar entre épocas de semeadura podem ser, então, associadas com os fotoperíodos diferentes a que as plantas estavam expostas nas diferentes épocas de semeadura. A análise do NFF em função do fotoperíodo acumulado (FA) durante a fase indutiva revelou aumento linear do NFF com o fotoperíodo acumulado em todas as cultivares com $R^{2}$ que variou de 0,77 a 0,95 (Figura 5). Esses resultados sugerem que existe resposta fotoperiódica nas cultivares estudadas e a relação linear positiva entre NFF e FA indica uma resposta típica de planta de dia curto, ou seja, quanto menor o fotoperíodo, menor o NFF e menor a duração do ciclo de desenvolvimento. 

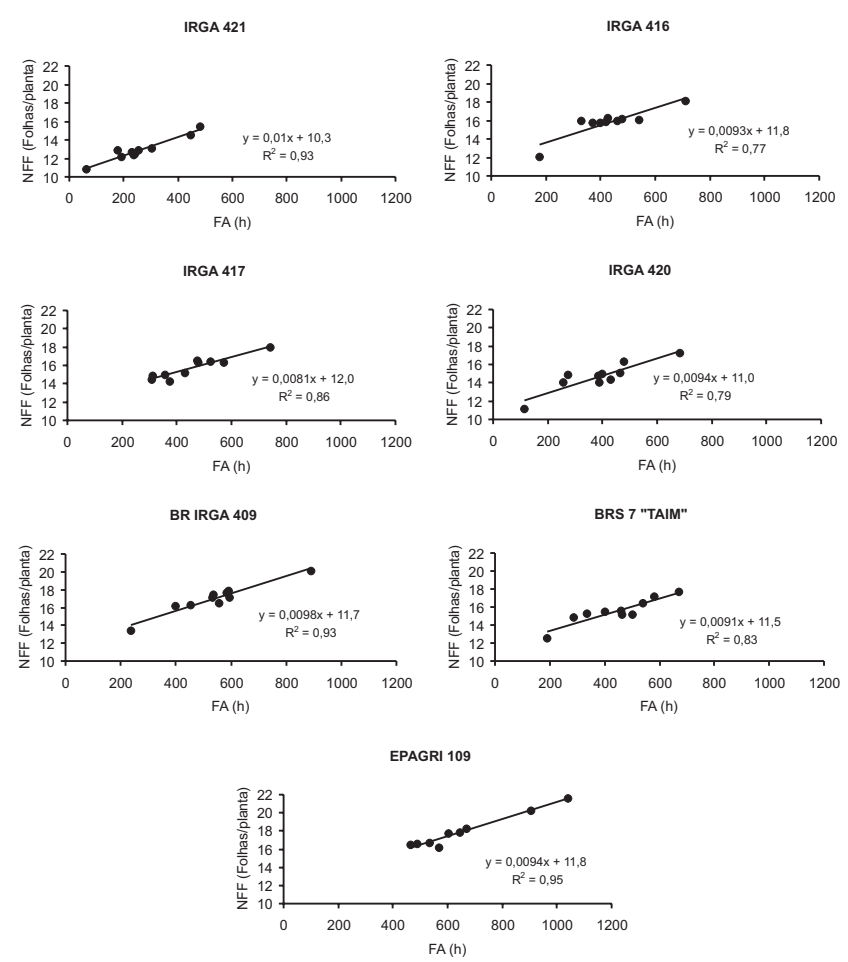

Figura 5. Relação entre o número final de folhas no colmo principal (NFF) de plantas de cultivares de arroz e fotoperíodo acumulado (FA) durante a fase indutiva. Os dados de NFF de dois anos agrícolas (2003/2004 e 2004/ 2005) foram agrupados no mesmo gráfico. Santa Maria, RS.

A sensibilidade ao fotoperíodo depende do genótipo de arroz e pode ser medida pelo valor do coeficiente angular ou declividade da regressão linear entre dias até o florescimento e a data de semeadura (FUKAI, 1999). Quanto maior o coeficiente angular, maior a sensibilidade do genótipo ao fotoperíodo. Utilizando essa relação, FUKaI (1999) classificou vários genótipos de arroz em três grupos: insensível, medianamente sensível e altamente sensível. Essa relação é apropriada para regiões tropicais, onde a temperatura do ar não é limitante para o crescimento e desenvolvimento do arroz. No entanto, para regiões subtropicais como o sul do Brasil, tal relação não é apropriada, pois em semeaduras tardias, devido às baixas temperaturas (Figura 1), as plantas não florescem, ou se florescem, ocorre após longo período, o que pode causar equívocos na interpretação dos resultados e possíveis erros na classificação. No presente trabalho utilizou-se o coeficiente angular da relação NFF x FA para classificar as cultivares. Considerando-se o coeficiente angular das relações apresentadas na Figura 5 tem-se, em ordem decrescente de sensibilidade ao fotoperíodo, as cultivares IRGA $421>$ BR-IRGA $409>$ IRGA $420=$ EPAGRI 109 > IRGA 416 > BRS 7 “Taim" > IRGA 417.
FuKaI (1999) também demonstrou que nas cultivares de arroz altamente sensíveis ao fotoperíodo o coeficiente de determinação $\left(R^{2}\right)$ da relação dias até o florescimento versus data de semeadura foi acima de 0,85 ; para o grupo de cultivares medianamente sensíveis, o $R^{2}$ variou de 0,64 a 0,85 e para o grupo de cultivares insensíveis ao fotoperíodo, o $R^{2}$ variou de 0,24 a 0,64 . Os valores de $R^{2}$ da Figura 5 permitem classificar as cultivares em dois grupos: altamente sensíveis ao fotoperíodo (IRGA 421, BR-IRGA 409, EPAGRI 109 e IRGA 417) e medianamente sensíveis ao fotoperíodo (BRS 7 "Taim”, IRGA 420 e IRGA 416).

Independentemente do critério para classificar os genótipos (coeficiente angular ou $\mathrm{R}^{2}$ ), todas as cultivares avaliadas tiveram alguma resposta fotoperiódica. Esses resultados confirmam uma resposta fotoperiódica de genótipos de arroz da subespécie indica identificado em outros estudos em diversas partes do Globo (VERGARA, 1969; BAKER et al., 1990; HORIE, 1994; FUKAI, 1999).

O conhecimento da resposta fotoperiódica de genótipos de arroz é uma informação básica importante que pode auxiliar no planejamento da cultura de arroz tanto em regiões tropicais quanto em regiões subtropicais. Nas regiões tropicais, a temperatura normalmente não é um fator ecológico limitante para o cultivo de arroz, mas nessas regiões é preferível a realização do cultivo de arroz durante a época de chuva das monções para aproveitar a água disponível no solo oriunda da precipitação pluvial e assim diminuir os custos de produção (FUKAI, 1999). Para que a cultura complete seu ciclo de desenvolvimento durante o período de chuvas nessas regiões, são preferidos os genótipos que respondem ao fotoperíodo (FUKAI, 1999). Nas regiões subtropicais, por sua vez, a época recomendada para semeadura é restrita a um ou dois meses na primavera para que as fases críticas (microsporogênese e antese) ocorram antes da chegada das baixas temperaturas, no fim do verão. Uma resposta fotoperiódica associada com a seleção de genótipos de ciclo adequado ajuda a adequar o ciclo de desenvolvimento do arroz de modo que as temperaturas baixas não causem danos fisiológicos. Um exemplo é a cultivar muito precoce IRGA 421, com rendimento de grãos potencial 3 a $4 \mathrm{t}$ ha $^{-1}$ menor do que em outras cultivares como o BR IRGA 409 e IRGA417, quando semeadas na época recomendada no Rio Grande do Sul (MARIOT et al., 2005). No entanto, essa cultivar é recomendada e tem o rendimento de grãos superior ao rendimento das outras cultivares em semeaduras tardias fora da época recomendada (por exemplo em dezembro, no Estado do Rio Grande do Sul, por razões diversas em que o agricultor não consegue semear na época recomendada). 
Em tais situações, na cultivar IRGA 421, a fase emergência - antese, e a floração se completam rapidamente e ocorrem quando as temperaturas no fim do verão (fevereiro) ainda não são limitantes, o que não se observa em outras cultivares, que florecem em março quando as temperaturas são baixas. A curta duração da fase emergência-antese da cultivar IRGA 421 ocorre devido ao menor NFF ( 2 a 6 folhas menos do que as outras cultivares neste estudo), e a semeadura tardia diminui ainda mais o NFF (Figura 4) decorrente de sua resposta fotoperiódica.

Em regiões subtropicais, também é importante que se conheça a resposta fotoperiódica dos genótipos de arroz, por exemplo, em estudos de mudanças climáticas que projetam aumentos na temperatura do ar (MARQUES et al., 2005). Em tais cenários, a resposta fotoperiódica dos genótipos pode ter um papel marcante no ciclo de desenvolvimento e, conseqüentemente, no rendimento de grãos de arroz diante de possível aumento de temperatura do ar. Portanto, recomenda-se que em estudos do impacto de mudança climática sobre o desempenho de agroecossistemas de arroz, a resposta fotoperiódica seja considerada na simulação das datas de ocorrência dos estágios de desenvolvimento dessa cultura.

\section{CONCLUSÃO}

1. O número final de folhas no colmo principal (NFF) de plantas de arroz variou com o genótipo, com a época de semeadura e o ano agrícola.

2. A variação do NFF com a época de semeadura revela que existe resposta ao fotoperíodo nos genótipos de arroz avaliados, com resposta típica de planta de dia curto.

3. Existe diferença de sensibilidade ao fotoperíodo entre as cultivares de arroz da mesma subespécie.

\section{AGRADECIMENTOS}

Ao Instituto Rio Grandense do Arroz (IRGA), pela ajuda financeira no primeiro ano e pelo fornecimento das sementes nos dois anos deste estudo. Aos revisores Ad Hoc, pelas valiosas sugestões e comentários nas versões anteriores deste manuscrito.

\section{REFERÊNCIAS}

BAKER, J.T.; ALLEN Jr., L.H.; BOOTE, K.J.; JONES, P.; JONES, J.W. Developmental responses of rice to photoperiod and carbon dioxide concentration. Agricultural and Forest Meteorology, Amsterdam, v.50, p.201-210, 1990.
COOPER, M.; RAJATASEREEKUL, S.; IMMARK, S.; FUKAI, S.; BASNAYAKE, J. Rainfed lowland rice breeding strategies for northeast Thailand. I. Genotypic variation and genotype $x$ environment interactions for grain yield. Field Crops Research, Amsterdam, v.64, p.131-151, 1999.

COUNCE, P.; KEISLING, T.C.; MITCHELL, A.J. A uniform, objective, and adaptive system for expressing rice development. Crop Science, Madison, v.40, n.2, p.436-443, 2000.

EMBRAPA. Sistema Brasileiro de Classificação de Solos. Brasília: Embrapa-SPI; Embrapa-CNPS, 1999. 412 p.

FAPEMIG. Orizicultura Melhorada. Disponível em: http:/ / www. revista.fapemig.br/ Acesso em 8 de novembro de 2005.

FERREIRA, C.M.; PINHEIRO, B.S; SOUSA, I.S.F.; MORAIS, O.P. Qualidade do arroz no Brasil: Evolução e padronização. Santo Antônio de Goiás: Embrapa Arroz e Feijão, 2005. 61 p.

FUKAI, S. Phenology in rainfed lowland rice. Field Crops Research, Amsterdam, v.64. n.1, p.51-60, 1999.

GAO, L.; JUN, Z.; HUANG, Y.; ZHANG, L. Rice clock model a computer model to simulate rice development. Agricultural and Forest Meteorology, Amsterdam, v. 60, n.1, p.1-16, 1992.

HODGES, T. Predicting crop phenology. Boca Rat: CRC, 1991. $233 \mathrm{p}$.

HORIE, T. Crop ontogeny and development. In: Physiology and determination of crop yield. Madison: ASA, SSSA, p. 153180, 1994.

HORIE, T.; NAKAGAWA, H. Modeling and predicting developmental process in rice. I. Structure and method of parameter estimation of a model for simulating developmental process towards heading. Japanese Journal of Crop Science, Tokyo, v.59, n.4, p. 687-695, 1990.

IRGA. Dados de safra: Série histórica da área plantada, produção e rendimento. Disponível em: http:// www.irga.rs.gov.br/dados.htm. Acesso em 15 de junho de 2005.

KAWAKATA, T.; YAJIMA, M. Modeling flowering time in rice under natural photoperiod and constant air temperature. Agronomy Journal, Madison. v.87, n.3, p.393-396, 1995.

KIESLING, T. C. Calculation of the length of the day. Agronomy Journal, Madison, v.74, p.758-759, 1982.

LEE, C. K.; LEE, B.W.; JHIN, J.C.; YOON, Y.H. Heading date and final leaf number as affected by sowing date and prediction of heading date based on leaf appearance model in rice. Korean Journal of Crop Science, Seoul, v.46, n.3, p.195-201, 2001.

LUZZARDI, R.; SARAIVA, C. T.; BOCK, F.; WEBER, L.; PASQUALLI, L. Avaliação preliminar da produtividade em campo e qualidade industrial de híbridos de arroz no Rio Grande do Sul. In: CONGRESSO BRASILEIRO DE ARROZ IRRIGADO, 4, 2005, Santa Maria. Anais... Santa Maria: Sociedade Sul-Brasileira de Arroz Irrigado, 2005. v.1, p.70-72. 
MARIOT, C.H.P.; MENEZEZ, V.G.; LIMA, S.L.; RAMIREZ,H.V.; NEVES, G. Influência de época de semeadura no rendimento de grãos de cultivares de arroz irrigado - safras 2003/04 e 2004/ 05. Santa Maria, RS, 2005. In: CONGRESSO BRASILEIRO DE ARROZ IRRIGADO, 4, 2005, Santa Maria. Anais... Santa Maria: Sociedade Sul-Brasileira de Arroz Irrigado, 2005. v.1, p.251-253.

MARQUES,J.R.Q.;STEINMETZ,S.; DINIZ, G.;SIQUEIRA,O.J.W.; WREGE, M.S.; HERTER, F.G.; REISSER, C.J. Aumento da temperatura mínima do ar no Rio Grande do Sul, sua relação com o aquecimento global e possíveis impactos no arroz irrigado. Santa Maria, RS, 2005. In: CONGRESSO BRASILEIRO DE ARROZ IRRIGADO, 4, 2005, Santa Maria. Anais. Santa Maria: Sociedade Sul-Brasileira de Arroz Irrigado, 2005. v.1, p.224-226.

MICHELON, S. Crescimento e desenvolvimento de genótipos de arroz cultivado (Oryza sativa L.) e de biótipos de arroz vermelho (Oryza sativa L.). 2006. 92f. Dissertação (Mestrado em Agronomia) - Programa de Pós-Graduação em Agronomia - Universidade Federal de Santa Maria.

MORENO, J.A. Clima do Rio Grande do Sul. Porto Alegre: Secretaria de Agricultura, Diretoria de Terras e Colonização, Secção de Geografia, 1961. 43p.

SIÉ, M.; DINGKUHN, M.; WOPEREIS, M.C.S.; MIEZAN, K.M. Rice crop duration and leaf appearance rate in a variable thermal environment. I. Development of an empirically based model. Field Crops Research, Amsterdam, v.57, n.1, p.1-13, 1998.

SOSBAI (Sociedade Sul Brasileira de Arroz irrigado). Arroz irrigado: Recomendações técnicas para o sul do Brasil. Santa Maria: SOSBAI, 2005. 159p.

STRECK, N.A.; BOSCO, L.C.; MICHELON, S.; WALTER, L.C.; MARCOLIN, E. Duração do ciclo de desenvolvimento de cultivares de arroz em função da emissão de folhas. Ciência Rural, v. 36, n.4, p. 1086-1093, 2006.
SUMMERFIELD, R.J.; COLLINSON, S.T.; ELLIS, E.H.; ROBERTS, E.M.; PENNING DE VRIES, F.W. Photothermal responses of flowering in rice (Oryza sativa). Annals of Botany, Oxford, v.69, n.2, p.101-112, 1992.

USDA. Rice Area, Yield and Production. Disponível em http:/ /www.faz.usda.gov/psd. Acesso em 2 de setembro de 2005.

VERGARA, B.S.; CHANG, T.T.; LILIS, R. The flowering response of the rice plant to photoperiod: A review of the literature. Los Baños: Internacional Rice Research Institute, 1969. 28p. (Technical Bulletin. n. 8)

WADE, L.J.; MCLAREN, C.G.; QUINTANA, L.; HARNPICHITVITAYA, D.; RAJATASEREEKUL S.; SARAWGI, A.K.; KUMAR, A.; AHMED, H.U.; SARWOTO, SINGH, A.K.; RODRIGUEZ, R.; SIOPONGCO, J.; SARKARUNG, S. Genotype by environment interactions in diverse rainfed lowland rice environments. Field Crops Research, Amsterdam, v. 64, n.1, p.35-50, 1999.

YIN, X.; KROPFF, M. Use of the beta function to quantify effects on flowering and leaf number in rice. Agricultural and Forest Meteorology, Amsterdam, v.81, n.2, p.217 -228, 1996.

YIN, X.; KROPFF, M. The effect of photoperiod on interval between panicle initation and flowering in rice. Field Crops Research, Amsterdam, v.57, p.301- 307, 1998.

YIN, X.; KROPFF, M.; YNALVEZ, M.A. Photoperiodically sensitive and insensitive phases of preflowering development in rice. Crop Science, Madison, v.37, p.182 - 190, 1997a.

YIN, X.; KROPFF, M. J.; HORIE, T.; NAKAGAWA, H.; CENTENO, H.G.S.; ZHU, D.; GOUDRIAAN, J. A model for photothermal responses of flowering in rice. I - Model description and parameterization. Field Crops Research, Amsterdam, v.51, n.3, p.189 - 200, 1997b. 